\title{
Maturação fisiológica de sementes de Eugenia pyriformis Cambess e Eugenia involucrata DC.
}

\author{
Priscilla Oro * \\ Deisinara Giane Schulz \\ Cátia Raquel Volkweis \\ Karoline Branco Bandeira \\ Ubirajara Contro Malavasi \\ Marlene Matos Malavasi \\ Universidade Estadual do Oeste do Paraná \\ Rua Pernambuco, 1777, Caixa Postal 91, CEP 85960-000, Marechal Cândido Rondon - PR, Brasil \\ * Autor para correspondência \\ pri_oro@hotmail.com
}

Submetido em $17 / 10 / 2011$

Aceito para publicação em 21/05/2012

\section{Resumo}

O gênero Eugenia apresenta muitas espécies frutíferas com potencial para cultivo. Este estudo objetivou analisar a maturação fisiológica de sementes de Eugenia pyriformis Cambess e de Eugenia involucrata DC. Os frutos foram coletados manualmente em oito árvores adultas no município de Santa Helena, PR. Eles foram caracterizados em quatro estádios de acordo com a coloração para E. pyriformis e em cinco estádios para E. involucrata. As avaliações consistiram no teste de germinação, cálculo do tempo médio de germinação, determinação da massa seca e do grau de umidade das sementes. O delineamento adotado foi o inteiramente casualizado, com quatro repetições de 25 sementes. Os dados foram submetidos à análise de variância e as médias comparadas pelo teste de Tukey a $5 \%$ de probabilidade. A coloração dos frutos de E. pyriformis e de $E$. involucrata pode ser utilizada como parâmetro na avaliação da maturidade fisiológica das sementes. Sugere-se a coleta das sementes de E. pyriformis entre os estádios de coloração dos frutos verde/amarelo e amarelo/laranja e no estádio de coloração dos frutos vermelho-claro em relação a E. involucrata.

Palavras-chave: Cerejeira-do-mato; Coleta; Maturidade fisiológica; Uvaia

\section{Abstract}

Physiological maturation of seeds of Eugenia pyriformis Cambess and Eugenia involucrata DC. The genus Eugenia presents several fruit species with a potential for cultivation. This study aimed to analyze the physiological maturation of seeds of Eugenia pyriformis Cambess and Eugenia involucrata DC. Fruits were manually collected from eight adult trees in the town of Santa Helena, Parana, Brazil. They were characterized into four stages according to pigmentation for E. pyriformis and into five stages for E. involucrata. The evaluations consisted of germination test, mean germination time calculation, and determination of seeds dry weight and moisture content. The design adopted was completely randomized, with four replications of 25 seeds. Data 
underwent a variance analysis and the average values were compared through Tukey test at $5 \%$ probability. The pigmentation of E. pyriformis and E. involucrata fruits may be used as a parameter for the evaluation of physiological maturity of seeds. One suggests collecting seeds of $E$. pyriformis between the green/yellow and yellow/orange fruit pigmentation stages, and in the bright red fruit pigmentation stage regarding E. involucrata.

Key words: Cherry-of-the-Rio Grande; Collection; Physiological maturity; Uvaia

\section{Introdução}

O processo de maturação de frutos e sementes possui relevância em programas de melhoramento, tecnologia de sementes, conservação e produção de mudas. O acompanhamento do processo de maturação permite identificar o momento ideal de colheita das sementes, sendo a sua determinação fundamental para todas as espécies (ALVES et al., 2005; IOSSI et al., 2007).

A maturidade fisiológica das sementes é geralmente acompanhada por visíveis mudanças no aspecto externo e na coloração dos frutos e das sementes (SOUZA; LIMA, 1985; FIGLIOLIA, 1995; ALVES et al., 2005). Esse fator pode ser considerado um índice na determinação da maturidade fisiológica (FIGLIOLIA et al., 1993; FONSECA et al., 2005; DRANSKI et al., 2010) quando é atingido o máximo do peso de matéria seca das sementes, da germinação e do vigor (POPINIGIS, 1985; CARVALHO; NAKAGAWA, 2000).

O amadurecimento dos frutos está relacionado com a síntese de novos pigmentos como os carotenóides, com a degradação das clorofilas a e b, com a degradação de pigmentos subjacentes e com as mudanças na textura (HULME, 1971; PANTASTICO, 1975; DOMINGUES et al., 2001).

Entre as espécies da família Myrtaceae há várias espécies com valor frutífero e ornamental (SANTOS et al., 2004). Segundo Andersen e Andersen (1988), a uvaia (Eugenia pyriformis Cambess) é uma das frutíferas de grande potencial para cultivo, principalmente por agricultores familiares, podendo compor um sistema agrossilvipastoril. Os frutos apresentam potencialidade para uso industrial. Contudo, sua alta perecibilidade restringe a comercialização in natura (SCALON et al., 2004).

Eugenia involucrata DC., conhecida como cerejeira-do-mato, cerejeira-do-rio-grande, cerejeirada-terra, pitanga-preta, araçazeiro ou cerejeira
(CARVALHO, 2008), é cultivada inexpressivamente em pomares domésticos nas regiões Sul e Sudeste do país (LORENZI et al., 2006; SOUZA; LORENZI, 2008) e necessita de estudos que visem o seu manejo e melhoramento genético (DEGENHARDT et al., 2007).

$\mathrm{O}$ conhecimento relacionado à determinação de métodos que caracterizem a germinação de sementes de espécies florestais reveste-se de relevância para garantir a qualidade fisiológica e o vigor das sementes. Deste modo, este estudo objetivou estudar a maturação fisiológica das sementes de Eugenia pyriformis Cambess e de Eugenia involucrata DC. visando caracterizar a melhor época de colheita dos frutos.

\section{Material e Métodos}

O experimento foi conduzido na Universidade Estadual do Oeste do Paraná, campus Marechal Cândido Rondon. Os frutos foram coletados manualmente em oito árvores adultas no município de Santa Helena, PR. O clima da região segundo classificação de Köppen é o subtropical úmido mesotérmico, com verões quentes (temperatura média superior a $22^{\circ} \mathrm{C}$ ) com tendência de concentração das chuvas nesse período, invernos com geadas pouco frequentes (temperatura média inferior a $18^{\circ} \mathrm{C}$ ) e precipitação média anual de $1.500 \mathrm{~mm}$.

O beneficiamento foi realizado através da remoção da polpa e da posterior lavagem das sementes em água corrente. Os frutos foram classificados visualmente de acordo com a coloração do epicarpo representativos dos estádios de maturação (Tabela 1) utilizando-se o Munsell color charts for plant tissues (MUNSELL, 1976).

O grau de umidade e a massa seca das sementes (MS) foram determinados pelo método da estufa a 105 $\pm 3^{\circ} \mathrm{C}$ por $24 \mathrm{~h}$ de acordo com Brasil (2009) utilizando quatro repetições de 25 sementes de cada estádio de maturação do fruto. 
TABELA 1: Coloração de frutos de Eugenia pyriformis Cambess e E. involucrata DC. em diferentes estádios de maturação.

\begin{tabular}{|c|c|c|c|c|c|}
\hline \multicolumn{3}{|c|}{ Eugenia involucrata DC. } & \multicolumn{3}{|c|}{ Eugenia pyriformis Cambess } \\
\hline $\begin{array}{c}\text { Coloração do } \\
\text { epicarpo }\end{array}$ & $\begin{array}{c}\text { Caracterização } \\
\text { visual }\end{array}$ & M* & $\begin{array}{c}\text { Coloração do } \\
\text { epicarpo }\end{array}$ & $\begin{array}{c}\text { Caracterização } \\
\text { visual }\end{array}$ & $\mathbf{M} *$ \\
\hline & Verde (V) & $\begin{array}{c}7.5 \mathrm{GY} \\
5 / 8\end{array}$ & & Verde (V) & $\begin{array}{l}5 \mathrm{Y} \\
8 / 8\end{array}$ \\
\hline & $\begin{array}{c}\text { Amarela com } \\
\text { manchas } \\
\text { vermelhas (AV) }\end{array}$ & $\begin{array}{c}2.5 \mathrm{Y} \\
8 / 8\end{array}$ & & $\begin{array}{l}\text { Verde-amarelo } \\
\text { (VA) }\end{array}$ & $\begin{array}{c}5 \mathrm{Y} \\
8 / 12\end{array}$ \\
\hline & $\begin{array}{l}\text { Vermelho claro } \\
\text { (VC) }\end{array}$ & $\begin{array}{l}5 \mathrm{R} \\
3 / 8\end{array}$ & & Laranja (L) & $\begin{array}{l}2.5 \mathrm{Y} \\
8 / 10\end{array}$ \\
\hline & Vinho (VI) & $\begin{array}{l}5 \mathrm{R} \\
3 / 2\end{array}$ & & $\begin{array}{l}\text { Coletados no } \\
\text { chão }(\mathrm{C})\end{array}$ & $\begin{array}{l}2.5 \mathrm{Y} \\
7 / 10\end{array}$ \\
\hline & $\begin{array}{c}\text { Coletados no } \\
\text { chão }(\mathrm{C})\end{array}$ & $\begin{array}{l}5 \mathrm{R} \\
3 / 2\end{array}$ & & & \\
\hline
\end{tabular}

$M^{*}$ : Munsell color charts for plant tissues.

Para o teste de germinação utilizou-se areia autoclavada sendo as sementes colocadas para germinar entre areia, e as bandejas acondicionadas em câmara de germinação (BOD) com fotoperíodo de $12 \mathrm{~h}$ de luz a $25^{\circ} \mathrm{C}$.

As sementes foram consideradas germinadas quando originaram plântulas normais (raiz e parte aérea) de acordo com BRASIL (2009). Para E. involucrata, a primeira contagem da germinação foi realizada quando as sementes apresentaram aproximadamente $50 \%$ de germinação (BRASIL, 2009). O mesmo não foi aplicado à E. pyriformis por não atender a quantia mínima de germinação na mesma época de avaliação. Em contrapartida, avaliou-se o número de sementes mortas desta espécie face ao elevado grau de deterioração.

Os cálculos de porcentagem, tempo médio, velocidade de germinação foram realizados conforme fórmulas citadas por Labouriau e Valadares (1976), sendo a velocidade de germinação avaliada apenas para E. involucrata.

Adicionalmente, para as plântulas de E. pyriformis foi determinada a massa seca da parte aérea (MAS) após secagem em estufa de circulação forçada de ar, à temperatura de $65^{\circ} \mathrm{C}$ até massa constante. A determinação do comprimento médio de raiz (CMR) das plântulas foi realizada com régua milimetrada da parte inicial da raiz ligada à semente até o ápice radicular. 
O peso de mil sementes foi obtido a partir da pesagem em balança analítica de 10 repetições de 100 sementes, sendo somados seus valores (BRASIL, 2009).

O delineamento experimental foi o inteiramente casualizado com quatro estádios de maturação e quatro repetições de 25 sementes para E. pyriformis, e cinco estádios de maturação com quatro repetições de 25 sementes para E. involucrata.

Os dados foram submetidos à análise de variância através do software SISVAR e as médias comparadas pelo teste de Tukey a 5\% de probabilidade e regressão linear para as variáveis MS e umidade de sementes (FERREIRA, 2007) sendo os dados de porcentagem e tempo médio de germinação previamente transformados em $\log$ (x) (PIMENTEL-GOMES, 1973).

\section{Resultados e Discussão}

Sementes de E. pyriformis apresentaram grau de umidade de $60 \%, 56 \%, 58 \%$ e $55 \%$ para os estádios de maturação do fruto caracterizado como verde, verde/ amarelo, laranja e os coletados no chão, respectivamente, não apresentando diferenças entre si (Tabela 2) enquanto o peso de mil sementes foi de $1,093 \mathrm{~kg}$.semente ${ }^{-1}$ para o estádio laranja.
O alto grau de umidade das sementes desta espécie é característico de sementes recalcitrantes que não sofrem dessecamento acentuado ao final da maturação, são dispersas com elevado grau de umidade permanecendo metabolicamente ativas, e podem germinar logo após a dispersão (ROBERTS; KING, 1980; PAMMENTER; BERJAK, 2000; FARIA et al., 2004).

Santana (2007) trabalhou com três estádios de maturação dos frutos de E. pyriformis e encontrou teores de água igualmente elevados de $66,8 \%$ para imaturos, $58,4 \%$ para intermediários, e $59,1 \%$ para maduros. Delgado e Barbedo (2007) reportaram com outras espécies do gênero e mostraram que o elevado teor de água é comum entre espécies do gênero Eugenia, como Eugenia uniflora (52,0\%), E. brasiliensis roxa (49,6\%), E. brasiliensis amarela (47,2\%), E. involucrata $(58,2 \%)$, E. umbelliflora (42,5\%), e E. cerasiflora (62,8\%).

A porcentagem de germinação de E. pyriformis foi maior $(\mathrm{p}<0,05)$ para sementes provenientes de frutos verde/amarelo (59\%), apresentando indícios de que as sementes atingiram o ponto de maturidade fisiológica neste estádio, embora não tenha diferido estatisticamente dos estádios amarelo/laranja e caídas no chão (Tabela 2). Resultados semelhantes foram reportados por Lazarotto et al. (2011) que estudaram o ponto de maturidade fisiológica em sementes de Erythrina crista-galli L.

TABELA 2: Viabilidade, grau de umidade e vigor de sementes de uvaia (Eugenia pyriformis) em diferentes estádios de maturação.

\begin{tabular}{|c|c|c|c|c|c|c|}
\hline $\begin{array}{l}\text { Estádio de } \\
\text { Maturacão }\end{array}$ & Germinação & $\begin{array}{l}\text { Sementes } \\
\text { mortas }\end{array}$ & $\begin{array}{l}\text { Grau de } \\
\text { umidade }\end{array}$ & \multirow{2}{*}{$\begin{array}{l}\text { TMG } \\
\text { (dias) }\end{array}$} & \multirow{2}{*}{$\begin{array}{l}\text { CMR } \\
(\mathrm{mm}) \\
\end{array}$} & \multirow{2}{*}{$\begin{array}{c}\text { MSA } \\
\left(\mathrm{kg}^{\left.-\mathrm{g}^{-1}\right)}\right.\end{array}$} \\
\hline & \multicolumn{3}{|c|}{$(\%)$} & & & \\
\hline Verde & $32 \mathrm{~b}$ & $33,6 \mathrm{a}$ & $60 \mathrm{a}$ & $18.8 \mathrm{a}$ & $5,7 \mathrm{ab}$ & $1,95 \mathrm{~b}$ \\
\hline $\begin{array}{c}\text { Verde/ } \\
\text { Amarelo }\end{array}$ & $59 \mathrm{a}$ & $9,6 \mathrm{~b}$ & $56 \mathrm{a}$ & $18.7 \mathrm{a}$ & $6,5 \mathrm{a}$ & $2,5 \mathrm{a}$ \\
\hline $\begin{array}{l}\text { Amarelo/ } \\
\text { Laranja }\end{array}$ & $47 \mathrm{ab}$ & $8,0 \mathrm{~b}$ & $58 \mathrm{a}$ & $18.5 \mathrm{a}$ & $5,5 \mathrm{ab}$ & $1,7 \mathrm{~b}$ \\
\hline $\begin{array}{c}\text { Caídas no } \\
\text { chão }\end{array}$ & $38,4 \mathrm{ab}$ & $16,8 \mathrm{ab}$ & $55 \mathrm{a}$ & $14,5 \mathrm{a}$ & $4,9 \mathrm{~b}$ & $1,8 \mathrm{~b}$ \\
\hline $\mathrm{CV} \%$ & 16,9 & 46,4 & 2.65 & 8,5 & 15,5 & 14,9 \\
\hline
\end{tabular}

*Médias seguidas de mesma letra na coluna, não diferem entre si pelo teste de Tukey a 5\% de probabilidade. CV - coeficiente de variação; TMG - Tempo médio de germinação; CMR - Comprimento médio de raiz; MSA - Massa seca parte aérea. 
e constataram a máxima porcentagem de germinação $(50 \%)$, como também a primeira contagem máxima (14\%) na oitava semana após antese, sendo indicativos de maturidade fisiológica para aquelas sementes.

Os menores valores para porcentagem de sementes mortas foram observados nos frutos verde/amarelo e amarelo/laranja e os maiores valores em frutos verdes (Tabela 2), indicando que o fruto colhido com coloração do epicarpo verde não se caracteriza como ponto de maturidade fisiológica em semente de E. pyriformis. Alexandre et al. (2006) estudaram três estádios de maturação de sementes de jabuticabeira, outra espécie da família Myrtaceae e observaram que as sementes provenientes do estádio do fruto firme e de coloração da epiderme atropurpúrea apresentaram o maior vigor e a maior porcentagem de germinação.

O tempo médio de germinação não foi diferente entre os estádios, mas os frutos caídos no chão tiveram suas sementes emergidas em média quatro dias antes dos outros estádios (14,5 dias) sendo que a germinação média ocorreu em 18 dias. A deiscência ou queda destes frutos pôde desencadear o processo germinativo, uma vez que as sementes intolerantes à dessecação podem apresentar viviparidade, ou seja, germinação ainda no próprio fruto (BARBEDO; MARCOS-FILHO, 1998). A queda dos frutos pode ainda ter favorecido a taxa de deterioração das sementes, o que ocasionou a emergência rápida, mas não necessariamente a germinação.
Houve diferenças no comprimento médio da raiz das plântulas, sendo os maiores valores $(6,5 \mathrm{~mm})$ observados nas plântulas oriundas de sementes de frutos do estádio verde/amarelado. A maior massa seca da parte aérea $\left(2,5 \mathrm{~g} \cdot\right.$ semente $\left.^{-1}\right)$ também foi proveniente dos frutos do estádio verde/amarelo (Tabela 2), caracterizando, desta forma, este estádio como o ideal para coleta de frutos de E. pyriformis e obtenção de sementes e plântulas com maior vigor.

Conforme Carvalho e Nakagawa (2000), sementes não completamente maduras podem germinar, resultando, contudo, em plântulas tão vigorosas como aquelas colhidas no estádio ideal de maturação fisiológica. Diante disso, infere-se que os frutos de E. pyriformis atingiram a maturidade fisiológica no estádio verde/ amarelo resultando em maior massa seca da parte aérea e maior desenvolvimento do sistema radicular das plântulas originadas daquelas sementes, como também, menores porcentagens de sementes mortas.

A massa seca das sementes de E. pyriformis foi descrita por uma equação de ordem quadrática, com os maiores valores de massa acumulados nos estádios de maturação verde/amarelo e amarelo/laranja, decrescendo após o estádio amarelo/laranja. Já com o grau de umidade das sementes obteve-se resposta linear, porém sem diferenças entre os estádios de maturação (Figura 1). Avila et al. (2009) obtiveram respostas similares para sementes de Eugenia uniflora, caracterizando a espécie

TABELA 3: Viabilidade, grau de umidade e vigor de sementes de cerejeira-do-mato (Eugenia involucrata) em diferentes estádios de maturação.

\begin{tabular}{|c|c|c|c|c|c|}
\hline \multirow{2}{*}{$\begin{array}{l}\text { Estádio de } \\
\text { maturação }\end{array}$} & Germinação & $\begin{array}{l}\text { Grau de } \\
\text { Umidade }\end{array}$ & $1^{\circ}$ contagem & TMG & VMG \\
\hline & \multicolumn{3}{|c|}{$(\%)$} & \multicolumn{2}{|c|}{ Dias } \\
\hline Verde & $65,2 \mathrm{ab}$ & $75,5 \mathrm{a}$ & $16,0 \mathrm{~b}$ & $32,19 \mathrm{a}$ & $0,030 \mathrm{a}$ \\
\hline Amarelo/vermelho & $77,0 \mathrm{ab}$ & $74,5 \mathrm{ab}$ & $40 a b$ & $29,75 \mathrm{ab}$ & $0,030 \mathrm{a}$ \\
\hline Vermelho claro & $90,5 \mathrm{a}$ & $72,1 \mathrm{bc}$ & $46 \mathrm{a}$ & $26,69 \mathrm{~b}$ & $0,037 \mathrm{~b}$ \\
\hline Vinho & $61,2 \mathrm{ab}$ & $70,9 \mathrm{c}$ & $36 \mathrm{ab}$ & $30,49 \mathrm{ab}$ & $0,032 \mathrm{ab}$ \\
\hline Caídos no chão & $62,0 \mathrm{~b}$ & $59,3 \mathrm{~d}$ & $28 \mathrm{ab}$ & $31,07 \mathrm{ab}$ & $0,030 \mathrm{a}$ \\
\hline CV $(\%)$ & 4,4 & 2,1 & 37,2 & 7,8 & 9,8 \\
\hline
\end{tabular}

*Médias seguidas de mesma letra na coluna, não diferem entre si pelo teste de Tukey a 5\% de probabilidade. CV - coeficiente de variação; TMG - tempo médio de germinação; VMG - velocidade média de germinação. 
como recalcitrante por conter elevado teor de água durante a maturação.

Sementes de E. involucrata apresentaram elevado grau de umidade (Tabela 3) sendo as sementes dos frutos caracterizados como estádio verde as que apresentaram os maiores valores $(75,5 \%)$, seguidas das do estádio amarelo/vermelho $(74,5 \%)$, vermelho claro $(72,3 \%)$, vinho $(70,9 \%)$ e do estádio de frutos caídos ao chão (59,3\%). O grau de umidade é um parâmetro diretamente associado a todos os aspectos relativos à qualidade fisiológica das sementes, sendo um dos indicadores para o período ideal de colheita (ANDRADE et al., 2001).

FIGURA 1: Acúmulo de massa seca e grau de umidade em sementes de Eugenia involucra $(1-\mathrm{V} ; 2-\mathrm{V} / \mathrm{V} ; 3-\mathrm{V} / \mathrm{C}$; 4-VI; 5- C/C) e Eugenia pyriformis (1-V; 2-V/A; 3-A/ L; 4-C/C. MS- Massa seca.
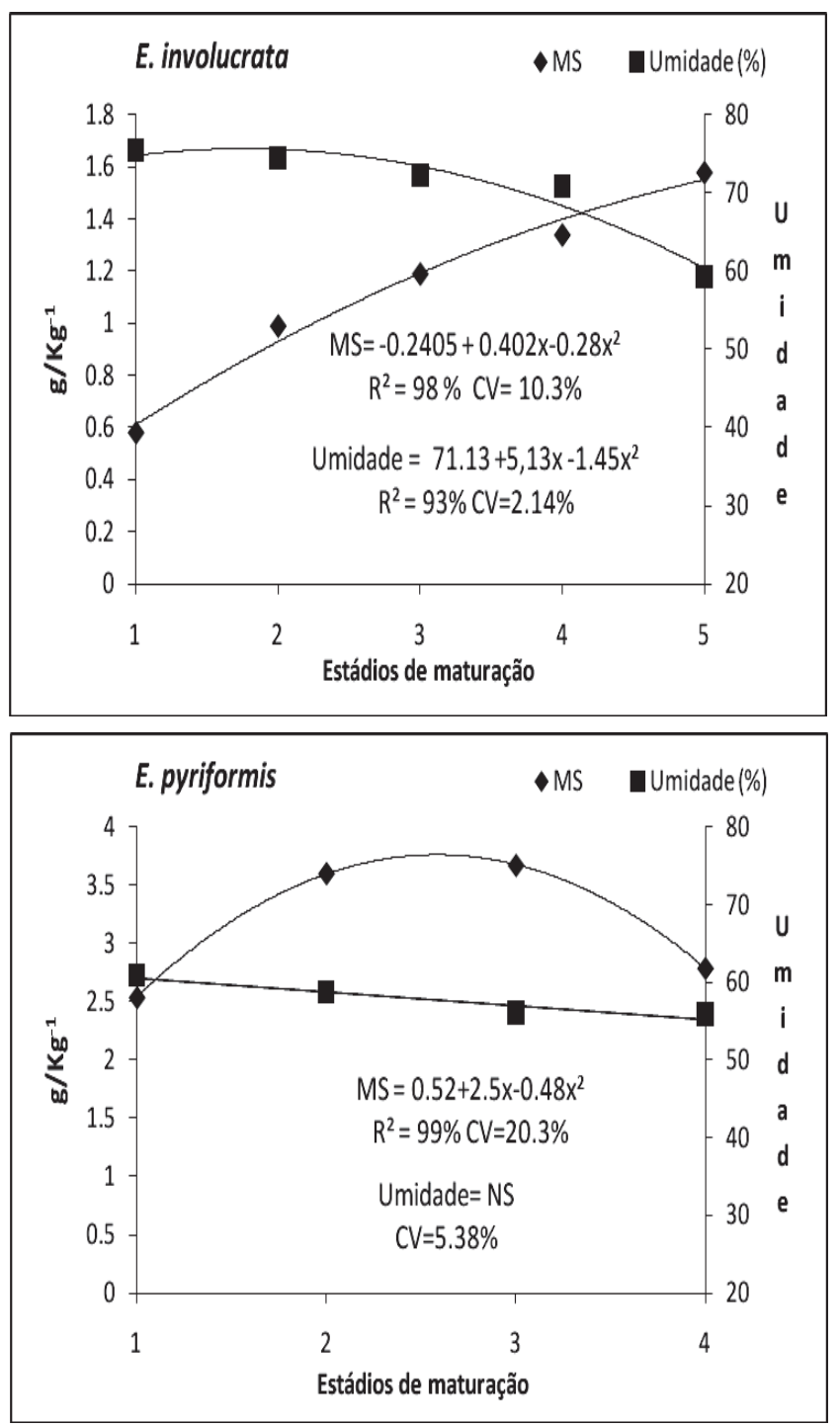

Um decréscimo quadrático pode ser observado no teor de água das sementes de cerejeira-do-mato com os menores valores obtidos em sementes de frutos categorizados como caídos no chão (Figura 1). Inversamente proporcional à perda de umidade, houve um rápido incremento no acúmulo de massa seca das sementes, tendendo a estabilizar após o estádio vermelho/claro, com a equação de ordem quadrática ajustada para esse parâmetro (Figura 1). A redução no peso verde das sementes está relacionada ao processo de secagem, de maturação ou dessecação, através do qual, após atingirem tamanho máximo, os valores de peso verde das sementes apresentam declínio (POPINIGIS, 1985; CASTRO et al., 2004).

Sementes de cerejeira-do-mato desenvolveram mais de uma plântula por semente, indicativo de embrião poliembriônico. Segundo Alexandre et al. (2006), sementes de jabuticabeira também apresentam esta característica e destacaram ainda que sementes as quais alcançaram a maturidade fisiológica favoreceram o desenvolvimento de maior número de embriões, pois todos já haviam atingido completo desenvolvimento e maturação fisiológica. No presente trabalho foi considerada apenas uma plântula por semente.

Detectaram-se diferenças na porcentagem de germinação de sementes, sendo os maiores valores alcançados em sementes provenientes do fruto no estádio vermelho claro $(90,5 \%)$ e os menores em frutos caídos no chão (62\%), possivelmente pelo início da deterioração das sementes dos frutos naquela situação. Semelhante ao presente estudo, Hirano e Possamai (2008) indicaram a colheita de frutos de imbuia, canela-sassafrás e canela-guaicá quando apresentarem a coloração verde e teor de umidade entre $63,2 \%, 57,3 \%$ e 34,1 a $48,5 \%$, respectivamente, a fim de evitar o ataque de insetos e a deterioração das sementes.

A primeira contagem de sementes foi considerada aos 28 dias devido ao pico de germinação observado, associado à porcentagem de germinação de $46 \%$ $(\mathrm{p}<0,05)$ em sementes no estádio de maturação vermelho claro. O tempo médio de germinação e a velocidade média de germinação das sementes de cerejeira-domato resultaram em diferenças para os estádios de maturação (Tabela 3), sendo a maior velocidade média 
alcançada nas sementes obtidas de frutos vermelho claro, diferenciando-se do estádio verde. O menor tempo médio também foi alcançado quando os frutos apresentaram a coloração vermelha claro, embora sem diferenças $(\mathrm{p}>0,05)$ em relação às sementes provenientes de frutos de coloração vinho, admitindo maior vigor das sementes nestes estádios. Medeiros et al. (2010) sugeriram que valores de velocidade de germinação assemelham-se com os de porcentagem de germinação de sementes, sendo um indicativo de maturidade fisiológica em sementes de maxixe (Cucumis anguria L.)

Os resultados indicam que a coloração do epicarpo dos frutos, a porcentagem de germinação, o acúmulo de massa seca de sementes, o comprimento de raiz e a massa seca da parte aérea podem ser utilizados como indicadores de maturidade fisiológica de sementes de Eugenia pyriformis.

Assim como, a coloração do epicarpo dos frutos, a porcentagem de germinação, o acúmulo de massa seca de sementes, a primeira contagem de sementes e a velocidade de germinação podem o ser para Eugenia involucrata.

Sugere-se a coleta das sementes de E. pyriformis quando seus frutos apresentarem coloração entre verde/ amarelo e amarelo/laranja e a coleta de sementes de $E$. involucrata quando a coloração dos frutos for vermelho claro.

\section{Agradecimentos}

À Coordenação de Aperfeiçoamento de Pessoal de Nível Superior - CAPES e, Conselho Nacional de Desenvolvimento Científico e Tecnológico-CNPq, pela concessão de bolsas.

\section{Referências}

ALEXANDRE, R. S.; WAGNER JÚNIOR, A.; NEGREIROS, J. R. S.; BRUCKNER, C. H. Estádio de maturação dos frutos e substratos na germinação de sementes e desenvolvimento inicial de plântulas de jabuticabeira. Revista Brasileira de Agrociência, Pelotas, v. 12, n. 2, p. 227-230, 2006.

ALVES, E. U.; SADER, R.; BRUNO, R. L. A.; ADRIA, A. U. Maturação fisiológica de sementes de sabiá. Revista Brasileira de Sementes, Londrina, v. 27, n. 1, p. 1-8, 2005.
ANDERSEN, O.; ANDERSEN, V. U. Uvaia. In: ANDERSEN, O.; ANDERSEN, V. U. As frutas silvestres brasileiras. Rio de Janeiro: Globo, 1988. p. 198-200.

ANDRADE, A. C. S.; RAMOS, F. N.; SOUZA, A. F.; LOUREIRO, M. B.; SOUZA, A. D. O.; CRUZ, A. P. M. Tamanho mínimo e preparo da amostra na determinação do grau de umidade de sementes de Parkia multijuga Benth. (Leguminosae - Mimosoideae). Revista Árvore, Viçosa, v. 25, n. 2, p. 203-207, 2001.

AVILA, A. L.; ARGENTA, M. S.; MUNIZ, M. F. B; POLETO, I.; BLUME, E. Maturação fisiológica e coleta de sementes de Eugenia uniflora L. (pitanga), Santa Maria, RS. Ciência Florestal, Santa Maria, v. 19, n. 1, p. 61-68, 2009.

BARBEDO, C. J.; MARCOS-FILHO, J. Tolerância à dessecação de sementes. Acta Botânica Brasilica, São Paulo. v. 12, n. 2, p. 145-164, 1998.

BRASIL. Ministério da Agricultura, Pecuária e Abastecimento. Regras para análise de sementes. Brasília: Secretaria de Defesa Agropecuária, Mapa/ACS, 2009. 399 p.

CARVALHO, N. M.; NAKAGAWA, J. Sementes, ciência, tecnologia e produção. 4. ed. Jaboticabal: FUNEP, 2000. 588 p.

CARVALHO, P. E. R. Espécies arbóreas brasileiras: recomendações silviculturais, potencialidade e uso da madeira. Brasília; Colombo: Embrapa Informações Tecnológicas; Embrapa Florestas, 2008. 593 p.

CASTRO, R. D.; BRADFORD, K. J.; HILHORST, H. W. M. Desenvolvimento de sementes e conteúdo de água. In: FERREIRA, A. G.; BORGHETTI, F. Germinação: do básico ao aplicado. Porto Alegre: Artmed, 2004. p. 51-68.

DEGENHARDT, J.; FRAZON, R. C.; COSTA, R. R. Cerejeirado-mato (Eugenia involucrata). (Embrapa Clima Temperado. Documentos, 211). Pelotas: Embrapa Clima Temperado, 2007. 31 p.

DELGADO, L. F.; BARBEDO, C. J. Tolerância à dessecação de sementes de espécies de Eugenia. Pesquisa Agropecuária Brasileira, Brasília, v. 42, n. 2, p. 265-272, 2007.

DOMINGUES, M. C. S.; ONO, E. O.; RODRIGUES, J. D. Indução do amadurecimento de frutos cítricos em pós-colheita com a aplicação de ethephon. Revista Brasileira de Fruticultura, Jaboticabal, v. 23, p. 555-558, 2001.

DRANSKI, J. A.; JÚNIOR, A. S. P.; STEINER, F.; ZOZ, Z.; MALAVASI, U.; MALAVASI, M.; GUIMARÃES, V. F. Physiological maturity of seeds and colorimetry of fruits of Jatropha curcas L. Revista Brasileira de Sementes, Londrina, v. 32, n. 4, p. 158-165, 2010.

FARIA, J. M. R.; LAMMEREN, A. A. M.; HILHORST, H. W. M. Desiccation sensitivity and cell cycle aspects in seeds of Inga vera subsp. affinis. Seed Science Research, Wallingford, v. 14, n. 2, p. 165-178, 2004

FERREIRA, D. F. Sisvar: sistema de análise de variância para dados balanceados, versão 5.1. Software estatístico, Lavras: DEX/ UFLA, 2007.

FIGLIOLIA, M. B. Colheita de sementes. IF série registros. Instituto Florestal, São Paulo, n. 14, p. 1-12, 1995.

FIGLIOLIA, M. B.; OLIVEIRA, E. DE C.; PIÑA-RODRIGUES, F. C. M. Análise de sementes. In: AGUIAR, I. B. DE; PIÑARODRIGUES, F. C. M; FIGLiOLiA, M. B. (Ed.). Sementes 
florestais tropicais. Brasília: Associação Brasileira de Tecnologia de Sementes, 1993. p. 137-174.

FONSECA, F. L.; MENEGARIO, C.; MORI, E. S.; NAKAGAWA, J. Maturidade fisiológica das sementes do ipê-amarelo, Tabebuia chrysotricha (Mart. Ex DC.) Standl. Scientia Florestalis, Piracicaba, n. 69, p. 163-141, 2005.

GUIMARÃES, D. M.; BARBOSA, J. M. Coloração dos frutos como índice de maturação para sementes de Machaerium brasiliense Vogel (Leguminosae - Fabaceae) Revista Brasileira de Biociências, Porto Alegre, v. 5, supl. 2, p. 567-569, 2007.

HIRANO, E.; POSSAMAI, E. Estádio de maturação do fruto e germinação de sementes de três espécies de Lauraceae. Scientia Agrária, Curitiba, v. 9, n. 2, p. 219-223, 2008.

HULME, A. C. The biochemistry of fruits and their products. London: Academic Press, 1971.

IOSSI, E.; SADER, R.; VITTIMORO, F.; BARBOSA, J. C. Maturação fisiológica de sementes de Phoenix roebelenii O'Brien. Revista Brasileira de Sementes, Brasília, v. 29, n. 1, p. 147-154, 2007.

LABOURIAU, L. G.; VALADARES, M. E. B. On the germination of seeds of Calotropis procera (Ait.) Ait. Anais da Academia Brasileira de Ciências, São Paulo, v. 48, p. 263-284. 1976.

LAZAROTTO, M.; BELTRAME, R.; MUNIZ, M. F. A.; BLUME, E. Maturação fisiológica de sementes de Erythrina crista-galli L. Ciência Florestal, Santa Maria, v. 21, n. 1, p. 9-16, 2011.

LORENZI, H.; BACHER, L.; LACERDA, M. T. C.; SARTORI, S. F. Frutas brasileiras e exóticas cultivadas: de consumo in natura. Nova Odessa: Plantarum, 2006. 640 p.

MEDEIROS, M. A.; GRANGEIRO L. C.; TORRES, S. B.; FREITAS, A. V. L. Maturação fisiológica de sementes de maxixe (Cucumis anguria L.). Revista Brasileira de Sementes, Londrina, v. 32, n. 3 p. $17-24,2010$.

MUNSELL, A. H. Munsell book of color. Baltimore: Macbeth Division of Kollmorgen, 1976. (Mathefinish collection). 20 p.
PAMMENTER, N. W.; BERJAK, P. Aspects of recalcitrant seed physiology. Revista Brasileira de Fisiologia Vegetal, Londrina, v. 12, p. 56-69, 2000. Edição Especial.

PANTASTICO, E. R. B. Postharvest physiology handling and utilization of tropical and subtropical fruits and vegetables. West Port: Avi, 1975. 560 p.

PIMENTEL-GOMES, F. Curso de estatística experimental. São Paulo: Nobel, 1973. 430 p.

POPINIGIS, F. Fisiologia da semente. Brasília: Agiplan, 1985. $289 \mathrm{p}$.

ROBERTS, E. H.; KING, M. W. The characteristics of recalcitrant seeds. In: CHIN, H. F.; ROBERTS, E. H. Recalcitrant crop seeds. Kuala Lumpur: Tropical Press, 1980. p. 1-5.

SANTANA, P. J. Maturação, secagem e armazenamento de sementes de espécies de Eugenia (Myrtaceae). 2007. 81 f. Dissertação (Mestrado em Biodiversidade Vegetal e Meio Ambiente) -Instituto de Botânica da Secretaria do Meio Ambiente, São Paulo, 2007.

SANTOS, C. M. R.; FERREIRA A. G.; ÁQUILA, M. E. A. Características de frutos e germinação de sementes de seis espécies de Myrtaceae nativas do Rio Grande do Sul. Ciência Florestal, Santa Maria, v. 14, n. 2, p. 13-20, 2004.

SCALON, S. P. Q.; SCALON FILHO, H.; RIGONI, M. R. Armazenamento e germinação de sementes de uvaia Eugenia uvalha Cambess. Ciência e Agrotecnologia, Lavras, v. 28, n. 6, p. 1228-1234, 2004.

SOUZA, S. M.; LIMA, P. C. F. Maturação de sementes de angico (Anadenanthera macrocarpa (Benth.) Brenan). Revista Brasileira de Sementes, Brasília, v. 7, n. 2, p. 93-99, 1985.

SOUZA, V. C.; LORENZI; H. Myrtaceae. In: SOUZA, V. C.; LORENZI; H. Botânica sistemática: guia ilustrado para identificação das famílias de fanerógamas nativas e exóticas do Brasil, baseado em APG II. 2. ed. Nova Odessa: Plantarum, 2008. p. 297-303. 